\title{
Drones y procesamiento de imágenes, una alternativa a la erradicación de malezas
}

\section{Drones and image processing, an alternative to weed eradication}

Yeison Alejandro Aldana ${ }^{1}$

()....

Recepción: 07/10/2020

Aprobación: 27/10/2020

()

Publicación: 18/10/2020

Para citar este artículo:

Aldana, Y. A. (2020). Drones y procesamiento de imágenes, una alternativa a la erradicación de malezas. Indagare, (8), 235-241. https://doi.org/10.35707/indagare/821

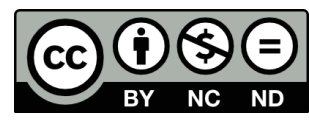

\footnotetext{
${ }^{1}$ Grupo de investigación D+TEC, Universidad de Ibagué, Colombia. Correo electrónico: yeison.aldana@unibague.edu.co
} 


\title{
Resumen
}

La investigación materia de estudio de este artículo aborda una solución alternativa para la erradicación de malezas en cultivos de arroz, a partir del procesamiento de imágenes obtenidas mediante vehículos aéreos no tripulados o drones. Este proyecto de investigación (Carvajal Montealegre, 2020) que permite identificar con gran precisión la maleza, toma un valor importante en términos del tiempo y la efectividad con la que se realizan los procesos de erradicación para la agricultura.

\begin{abstract}
The research subject of this article addresses an alternative solution for the eradication of weeds in rice crops, from the processing of images obtained through unmanned aerial vehicles or drones. This research project (Carvajal, 2020) that allows identifying the weed with high accuracy, takes an important value in terms of time and effectiveness with which the eradication processes are carried out for agriculture.
\end{abstract}

Palabras claves: Agricultura de precisión, drones, procesamiento de imágenes, técnicas de clasificación supervisadas.

Key words: Precision agriculture, drones, image processing, supervised classification techniques.

\section{Introducción}

La erradicación de malezas de forma convencional toma un nuevo rumbo con la agricultura de precisión y la incorporación de drones para la toma de imágenes que permiten identificar estas plantas silvestres no deseadas por los agricultores. Diferentes factores económicos, políticos y sociales en nuestro país, dificultan en gran manera el desarrollo, no solo de tecnologías para el agro, sino de programas para el crecimiento económico de los campesinos, que para el caso específico del arroz encuentran en investigaciones como esta, una solución que brinda apoyo a su labor diaria.

La producción de arroz en Colombia es menor a la de los otros países de la región, y con los tratados de libre comercio se ven afectados los productores locales, por lo cual se ve la necesidad de hacer un estudio que implemente tecnología en el campo para hacer la industria arrocera colombiana más competitiva, reduciendo costos y aumentando las ganancias, razón por la cual se han destinado fondos de entidades gubernamentales para el desarrollo de proyectos de este tipo. (A. Carvajal, comunicación personal, 27 de septiembre de 2020). 
INDAGA3E e-ISSN: 2357-5042 • Número 8 (2020) • Universidad de Ibagué • doi: https://doi.org/10.35707/indagare/821

La agricultura como fuente básica de obtención de alimento ha venido evolucionando no solo en la forma en la que se siembran los alimentos o en la que se recogen al terminar un ciclo de producción, sino también en la que se hace control de las malezas (Portafolio, 2019). Este ha sido un problema que se ha identificado de forma clara con anterioridad, dado que estas plantas silvestres no deseadas, toman recursos naturales que podrían ir de manera exclusiva para el cultivo, pero se ha tratado de diferentes maneras según la época y las herramientas disponibles. En la actualidad han aparecido diferentes soluciones que incluyen tecnología que ofrecen mejores resultados en cuanto a tiempo y costo de producción (Syngenta, 2017). Una de estas soluciones es el uso de vehículos aéreos no tripulados o conocidos como drones, para la obtención de fotografías de los cultivos, que permitan realizar posteriores procesamientos de imágenes, a través de las cuales se identifiquen zonas específicas de operación a la hora de la erradicación de malezas.

\section{Dron y cámaras}

Además del procesamiento de las imágenes que fue el protagonista de esta investigación, algunos de los instrumentos usados en este proyecto fueron el dron y las cámaras para obtener las fotografías en los sobrevuelos. Para el desarrollo de este proyecto se usó un dron multirotor DJI Matrice 200, de cuatro motores, con una dimensión de 89x88x38 cm y un rango de operación de 8 kilómetros y autonomía de 38 minutos. La cámara Red, Green, Blue (RGB) utilizada, a diferencia de las cámaras usadas de forma común, tiene una mayor resolución y apertura focal, es decir, indica qué tanto terreno puede abarcar en una sola toma, además tiene la capacidad de obtener imágenes y videos en $4 \mathrm{~K}$. Para este proyecto se hizo uso de la cámara Zenmuse X4S.

Por último, se usó una cámara multiespectral con la capacidad de captar diferentes rangos de longitudes de onda - hablando de la luz- e incluir aquellas imperceptibles para el ojo humano, por lo regular, las que se encuentran en el rango infrarrojo. De esta manera es más fácil el procesamiento de las imágenes. En este proyecto se usó la cámara de referencia Altum, de la marca Micasense para la fotografía multiespectral y especializada en el mapeo con drones para la agricultura. 
Figura 1. Dron y cámara multiespectral utilizados en el desarrollo del proyecto
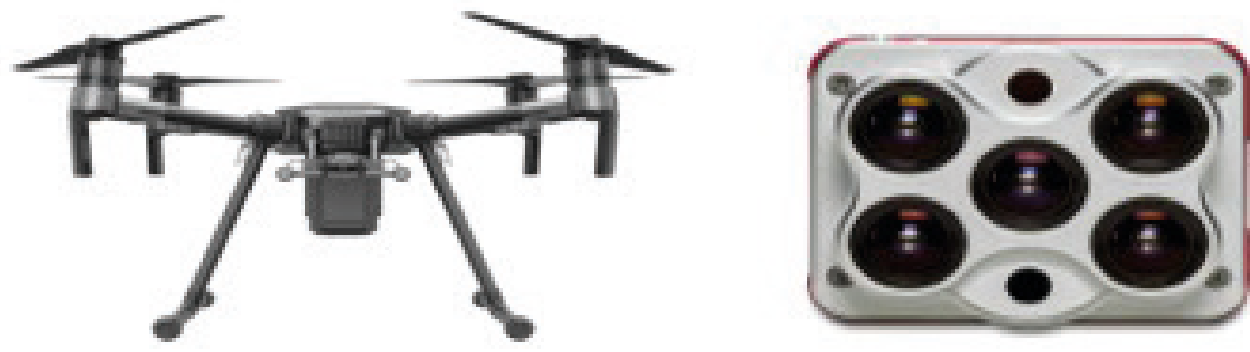

Fuente: Carvajal Montealegre, 2020

\section{Lugar donde se desarrolló la investigación}

El proyecto se desarrolló en dos etapas durante el año 2019, para evaluar la mayor cantidad de variables climatológicas. Los distritos de riego Usocoello, Usosaldaña y Asorrecio destinaron un lote para cada etapa en cada municipio: Espinal, Saldaña y Lérida respectivamente. En total fueron seis lotes de estudio, del tamaño de una hectárea cada uno, de la cual se usó solo $1 \frac{1}{4}$ de para cada caso. Secciones que a la vez se dividieron para aplicar diferentes cantidades de herbicida preemergente, para crear diversos escenarios de maleza y tener variedad en los datos por estudiar. En cada etapa fueron realizados dos sobrevuelos para la obtención de imágenes del cultivo, el primero, 15 días después de la siembra, donde se empiezan a notar los inicios de crecimiento de maleza, y el segundo, 30 días después de la siembra para control.

\section{Procesamiento de las imágenes}

Un primer paso fue la generación de ortomosaicos, que consiste en organizar, unir y calibrar de manera precisa las imágenes tomadas por las cámaras del dron, de tal forma que, al basarse en una posición registrada por un Sistema de Posicionamiento Global (GPS) incorporado en el dron en cada una de las imágenes, y teniendo en cuenta el traslape, que quiere decir que cada imagen tendrá una región en común con la siguiente, hará posible la creación de un mapa del recorrido realizado por el dron. Esto para la cámara RGB, mientras que para la cámara multiespectral, se realiza una corrección radiométrica, para unir después las imágenes tomadas por ambas y crear los ortomosaicos, uno en color (RGB) y otro en Índice de Vegetación de Diferencia Normalizada (NDVI). 
También se aplicó un realce para destacar las plantas del suelo y así poder diferenciar de una manera más fácil estos dos elementos, además de facilitar en gran parte posteriores procesamientos como lo muestra la Figura 2. La parte clara resaltada son las zonas verdes y la parte oscura el resto de terreno.

Figura 2. Ortomosaico con diferencia de color resaltado

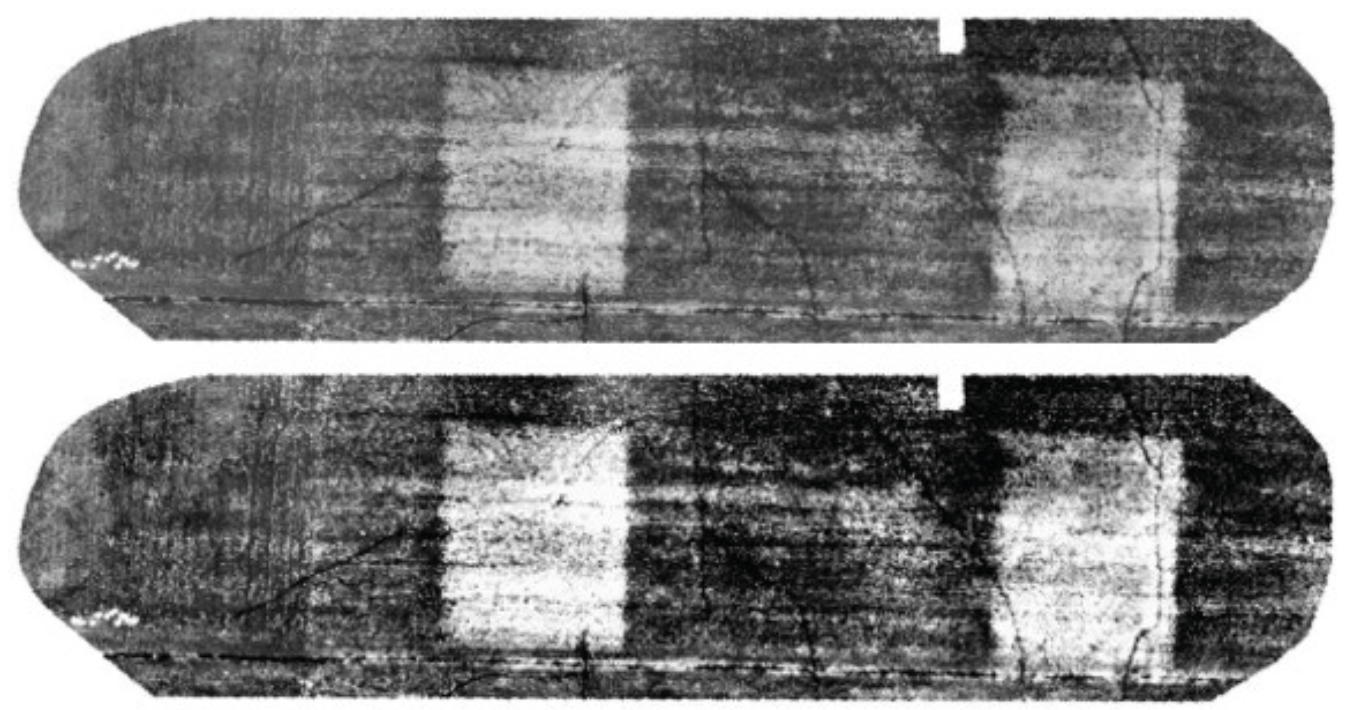

Fuente: Carvajal Montealegre, 2020

Un paso siguiente es crear grupos que tengan pixeles vecinos, es decir, zonas que contengan de forma consecutiva plantas o suelo. Para identificarlas se usan diferentes colores, a pesar de esto persiste la dificultad para diferenciar ciertos grupos, en zonas donde existen varios muy cerca. La imagen obtenida se guarda con georreferenciación para luego sobreponerla a la imagen del ortomosaico RGB de manera precisa como se muestra en la Figura 3. 
Figura 3. Ortomosaico con etiquetado de objetos

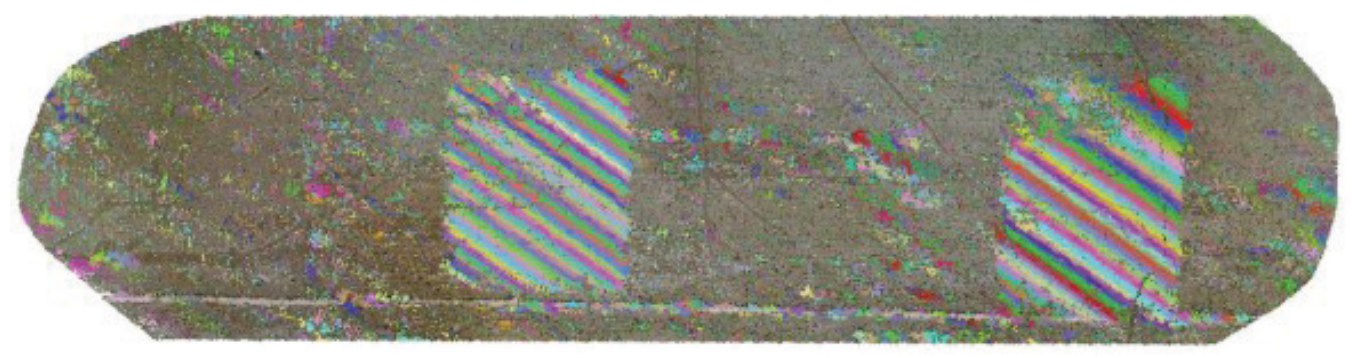

Fuente: Carvajal Montealegre, 2020

Con estas imágenes se procedió a utilizar descriptores, los cuales permiten caracterizar objetos. Es decir, darnos una idea de qué tipo de objeto se trata, dependiendo del descriptor. Se usaron 19 descriptores que se agruparon en tres categorías: de textura, forma y reflectancia del objeto. Con textura nos referimos a cuántas veces se repite un valor de pixel en una imagen, para esta categoría los descriptores más destacados son los de Haralick.

Para la categoría de la forma, como su nombre lo indica, el objetivo era encontrar características referentes a la forma del objeto. Esta categoría contuvo la mayoría de los descriptores, dentro de los cuales destacaron los momentos invariantes de $\mathrm{Hu}$, ampliamente usados en procesamiento de imágenes. Para la categoría de reflectancia se usó un único descriptor, el NDVI. Con base en los descriptores se usaron tres métodos de reducción de características: Análisis de Componentes Principales (PCA), distribución normal de los datos de cada clase y selección secuencial de características.

Luego de realizar estas reducciones a partir de los métodos antes mencionados, se combinaron los resultados para crear tres sistemas de clasificación de Random forest, tres de máquina de soporte vectorial y tres vecinos más cercanos, para un total de nueve. De lo anterior se observó que el sistema Random forest con reducción de características PCA fue la mejor de las combinaciones, con eficiencias cercanas al $90 \%$ en cuanto a la identificación de malezas. Un ejemplo de esto se muestra en la Figura 4a donde se observa un terreno sin identificar la maleza y, a su lado, en la Figura $4 \mathrm{~b}$, un terreno con la maleza ya identificada. 
INDAGA3E e-ISSN: 2357-5042 • Número 8 (2020) • Universidad de Ibagué • doi: https://doi.org/10.35707/indagare/821

Figura 4. Identificación de malezas con sistema Random forest con reducción de características PCA

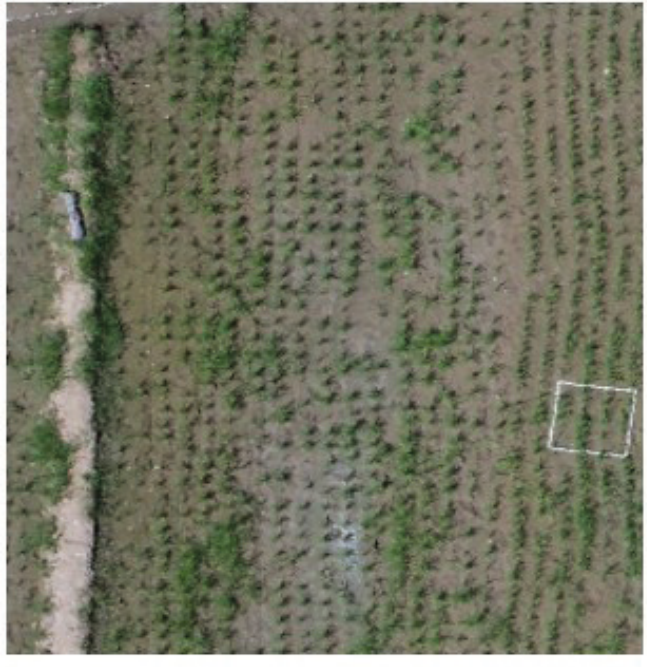

a)

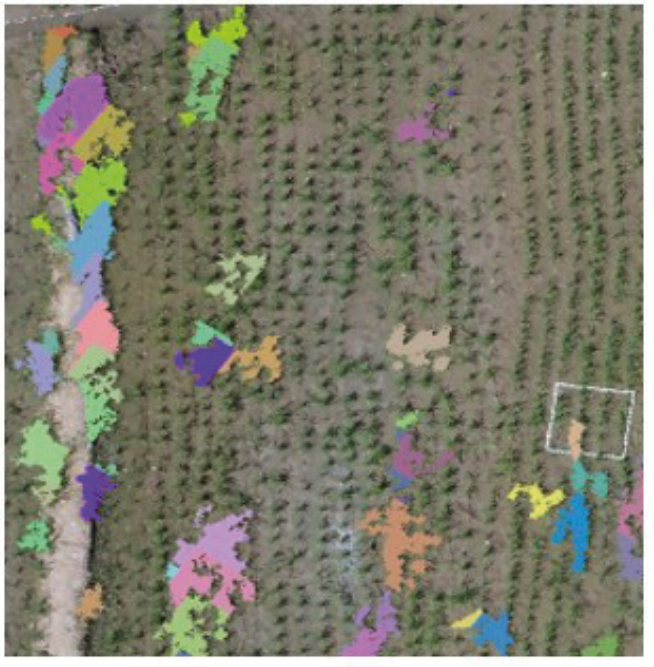

b)

Fuente: Carvajal Montealegre, 2020

\section{Conclusión}

El desarrollo de los sistemas de clasificación que permiten identificar con gran precisión la maleza a partir de imágenes tomadas desde vehículos aéreos no tripulados ofrece una gran posibilidad para los agricultores. La razón que sustenta lo anterior es porque no solo el tiempo toma un valor importante, sino también la efectividad con la que se realizan los procesos de erradicación, pues se opera en sitios específicos identificados con anterioridad.

\section{Referencias}

Carvajal Montealegre, A. (2020). Detección y localización de malezas en cultivos de arroz basados en el análisis de imágenes de reflectancia y RGB tomadas desde drones (Tesis de pregrado). Universidad de Ibagué, Tolima, Colombia.

Portafolio. (12 de febrero de 2019). Las tecnologías que podrán 'salvar' el agro colombiano. Portafolio. Recuperado de https://n9.cl/ea3w

Syngenta. (2017). Importancia del control temprano de malezas. Recuperado de https://n9.cl/hvri 